\title{
Effect of 0.3-Millisecond Multi-Pulsed 1064-nm Nd:YAG Laser in Patients with Postherpetic Neuralgia*
}

\author{
Koji Itai $^{1,2 \#}$, Ayumi Korekawa ${ }^{1}$, Kayo Jin ${ }^{1}$, Takayuki Aizu ${ }^{1}$, Akiko Rokunohe ${ }^{1}$, Chihiro Hagiwara ${ }^{1}$, \\ Katsumi Hanada $^{1}$, Daisuke Sawamura ${ }^{1 \#}$
}

${ }^{1}$ Department of Dermatology, Graduate School of Medicine, Hirosaki University, Hirosaki, Japan; ${ }^{2}$ Itai Institute of Laser and Cosmetic Medicine, Goshogawara, Japan.

Email: $\left\{\#\right.$ derm, ${ }^{\#}$ smartdai14\}@cc.hirosaki-u.ac.jp

Received December $22^{\text {nd }}, 2011$; revised January $10^{\text {th }}, 2012$; accepted January $20^{\text {th }}, 2012$

\begin{abstract}
Postherpetic neuralgia (PHN) is the most common complication following acute varicella zoster virus infection. PHN is associated with chronic severe pain and is resistant to conservative management treatments. The purpose of this study was to evaluate the effect of 0.3-millisecond multi-pulsed 1064-nm Nd:YAG laser treatment on PHN. Five subjects were treated with 2 - 3 sessions at 2-week interval. After the treatments, reduced visual analog scale (VAS) scores were noted in all patients. Treatments showed no adverse or intolerant effects and all patients felt warmth and comfort during the therapy. We first reported treating PHN patients using 0.3-millisecond multi-pulsed 1064-nm laser Nd:YAG. The results showed remarkable improvements in pain. This laser treatment could be an alternative choice for PHN patients with intractable neuralgia.
\end{abstract}

Keywords: Pain; Laser; Herpes Zoster

\section{Introduction}

Varicella zoster results from the infection with the varicella-zoster virus, and it is latently present in the dorsal root ganglion of the spinal cord [1]. The virus is then re-activated due to suppressed immune responses. In the skin areas in which the corresponding nerves are innervated, it produces a unilateral vesicular erythematous eruption and a related skin eruption. In addition, pain is concurrently present at the site of invasion. Since the skin is not healed but can progress to postherpetic neuralgia $(\mathrm{PHN})$.

PHN may interfere with quality of life in terms of physical, emotional, and social functioning as well as increase health care costs [2,3]. Medications such as opiates, tricyclic antidepressants, and anticonvulsants are currently recommended for the treatment of PHN. However, in clinical practice, these agents frequently lead to poor therapeutic response and intolerable side effects, especially in elder patients. Also, laser therapies such as soft laser, low power diode, or a He:Ne laser have been used to treat PHN $[4,5]$. However, once the pain level is fixed, PHN will be resistant to laser therapies.

Thus, there is a need for more effective and better tolerated therapies. In this study, we evaluated the efficacy

\footnotetext{
${ }^{*}$ The authors have no conflicts of interest to declare.

${ }^{\#}$ Corresponding author.
}

and safety of PHN using 0.3-millisecond multi-pulsed 1064-nm laser Nd:YAG.

\section{Material and Methods}

The patient group included four males and one female 74 - 86 years of age (Table). Patients with disseminated zoster or malignancy were excluded from the trial. All patients were properly treated with oral antiviral drugs for one week at the beginning of the herpes zoster (HZ) outbreak. They were also treated with nonsteroidal antiinflammatory drugs, antidepressants, anticonvulsants, and oral steroids. We selected the patients whose conditions were resistant to the treatments and fixed their symptoms. Each patient's pain severity was graded according to the visual analog scale (VAS), which have been widely used to measure pain intensity.

Five patients were treated with 2 - 3 sessions at 2week intervals using a Nd:YAG laser (PhotoRevelatio ${ }^{\mathrm{TM}}$, Sciton Inc., Palo Alto, CA). The setting used for the treatment was 0.3 milliseconds, $10 \mathrm{~J} / \mathrm{cm}^{2}, 5 \mathrm{~Hz}$, a total of 3.9 watts, $1000-2000$ pulses to maintain the temperature of the treated area. The painful area was irradiated to maintain the temperature of $41^{\circ} \mathrm{C}-43^{\circ} \mathrm{C}$ for about 5 minutes by moving the laser around like painting. After the treatment, the pain was reassessed using the VAS. Consent was obtained from all the patients and the study was 
Table 1. Patient information and treatment results.

\begin{tabular}{ccccclccc}
\hline $\begin{array}{c}\text { Patient } \\
\text { Number }\end{array}$ & Age/Sex & Area & $\begin{array}{c}\text { Period Since Starting } \\
\text { Pain Fix }\end{array}$ & VAS & \multicolumn{1}{c}{ Combined Therapy } & $\begin{array}{c}\text { Number of } \\
\text { Sessions }\end{array}$ & $\begin{array}{c}\text { Ending VAS } \\
\text { and Symptoms }\end{array}$ \\
\hline 1 & $86 / \mathrm{M}$ & Left L1-2 & 6 month & $4 / 10$ & Amitriptyline, clonazepam & 3 & $1 / 10$ \\
2 & $83 / \mathrm{M}$ & Right C2-Th1 & 1 month & $6 / 10$ & Pregabalin, clonazepam, mefenamic acid & 3 & $1 / 10$ \\
3 & $78 / \mathrm{M}$ & Right V3 & 6 month & $4 / 10$ & Pregabalin, mecobalamin, dexamethasone & 2 & $1 / 10$, Paralysis \\
4 & $82 / \mathrm{M}$ & Left V1 & 2 years & $3 / 10$ & Pregabalin, Chinese herbal medicine & 2 & $0 / 10$, Numbness \\
5 & $74 / \mathrm{F}$ & Left Th2-3 & 2 month & $4 / 10$ & Pregabalin, loxoprofen, Chinese herbal medicine & 2 & $2 / 10$ \\
\hline
\end{tabular}

approved by the ethical committee of the Itai Instutute of Laser and Cosmetic Medicine prior to the study.

\section{Results}

All 5 patients with PHN treated in this study reported pain improvement (Table 1). The mean \pm SD of VAS score was $4.2 \pm 1.1$ before the laser treatment and $1.0 \pm$ 0.7 after treatment. There was a statistically significant difference $(\mathrm{p}<0.01)$ between the 2 groups (Figure 1). We measured the surface temperature of the PHN area during treatment and could not find any difference between the treated and untreated healthy areas. However, pain and other discomfort was either reduced or resolved just after the treatment.

Treatment showed no adverse effects or intolerant feelings such as burning or pain. All of the patients felt warm and comfortable during and after the therapy. The pain did not recur for $\geq 3$ months after the last treatment.

\section{Discussion}

$\mathrm{PHN}$ is a complication of herpes zoster that is defined as

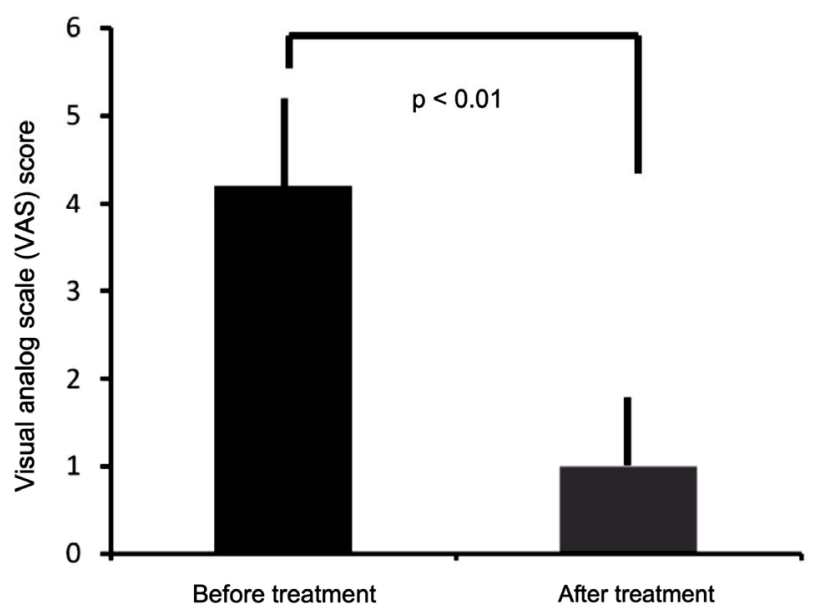

Figure 1. Improvement of PHN. Five patients were treated with 2 - 3 sessions at 2-week intervals using a Nd:YAG laser. Each patient's pain severity was graded according to the visual analog scale (VAS) before treatment. After the treatment, the pain was reassessed using the VAS. Data represents the means \pm SD of VAS score. There was a statistically significant difference $(p<0.01)$ between the 2 groups. pain that persists for $>4$ weeks after resolution of the $\mathrm{HZ}$ lesions. This neuralgia affects $16 \%$ of patients $<60$ years of age and about $47 \%$ of patients $>60$ years of age [6]. This neuralgic-type pain extends over the cutaneous area innervated by the affected nerve segment. The intensity of the pain may incapacitate the patient, making daily activities difficult and even preventing nocturnal rest, thus affecting the patient's psyche, humor, and resistance. The duration of the condition is imprecise, as it frequently becomes chronic; it can last for months or even years. The probability of its occurrence is higher in the elderly. Medical treatments instituted to date have produced only disappointing and frustrating results.

$\mathrm{Nd}$ :YAG lasers are one of the most common laser types and are used for many different applications. $\mathrm{Nd}$ : YAG lasers typically emit light with a wavelength of $1064 \mathrm{~nm}$ in the infrared. Nd:YAG lasers can be used in both non-ablative (low power) and ablative (high power) applications. Ablative treatments are usually reserved for skin resurfacing procedures and are more commonly used for treating acne scars [7]. Non-ablative treatments tend to be minimally invasive and appear to work by stimulating the growth of new skin tissue and increasing collagen production.

In this study, we were the first to report non-ablative PHN treatment using 0.3-millisecond multi-pulsed $\mathrm{Nd}$ : YAG 1064-nm laser. The results showed remarkable improvement in terms of pain and the patients felt great comfort after the treatment. Low power Nd:YAG laser irradiation did not induce any irreversible tissue damage, and the irradiated tissue demonstrated only mild capillary dilation [8]. On the other hand, the high laser power group also showed hemorrhaging and infiltration of inflammatory cells [9]. Although we did not mention precise mechanism whereby a non-ablative $\mathrm{Nd}$ :YAG laser has a feasible effect on PHN, capillary dilation might have an important role in pain improvement and it would accelerate elimination of the pain producing substances in the lesion. Also laser irradiation had some direct effects on exited neurons since it can reach the neuronal level. Further study is needed to investigate the mechanisms of Nf:YAG laser use for PHN and to seek a more effective clinical protocol. 


\section{REFERENCES}

[1] J. W. Gnann Jr. and R. J. Whitley, "Clinical Practice. Herpes Zoster," New England Journal of Medicine, Vol. 347, No. 5, 2002, pp. 340-346.

[2] A. Berger, E. M. Dukes and G. Oster, "Clinical Characteristics and Economic Costs of Patients with Painful Neuropathic Disorders," The Journal of Pain, Vol. 5, No. 3, 2004, pp. 143-149. doi:10.1016/j.jpain.2003.12.004

[3] R. H. Dworkin, R. White, A. B. O'Connor, O. Baser and K. Hawkins, "Healthcare Costs of Acute and Chronic Pain Associated with a Diagnosis of Herpes Zoster," Journal of the American Geriatrics Society, Vol. 65, No. 8, 2007, pp. 1168-1175. doi:10.1111/j.1532-5415.2007.01231.x

[4] I. Yaksich, L. C. Tan and V. Previn, "Low Energy Laser Therapy for Treatment of Post-Herpetic Neuralgia," Annals Academy of Medicine Singapore, Vol. 22, No. 3, 1993, pp. 441-442.

[5] K. Iijima, N. Shimoyama, M. Shimoyama and T. Mizuguchi, "Evaluation of Analgesic Effect of Low-Power He:Ne Laser on Postherpetic Neuralgia Using VAS and Modified McGill Pain Questionnaire," Journal of Clinical
Laser Medicine and Surgery, Vol. 9, No. 2, 1991, pp. 121-126.

[6] A. Volpi, G. Gross, J. Hercogova and R. W. Johnson, "Current Management of Herpes Zoster: The European View," American Journal of Clinical Dermatology, Vol. 6, No. 5, pp. 317-325. doi:10.2165/00128071-200506050-00005

[7] G. M. Lipper and M. Perez, "Nonablative Acne Scar Reduction after a Series of Treatments with a Short-Pulsed 1064-nm Neodymium:YAG Laser," Dermatologic Surgery, Vol. 32, No. 8, 2006, pp. 998-1006. doi:10.1111/j.1524-4725.2006.32222.x

[8] N. Beldüz, Y. Yilmaz, E. Ozbek, Y. Kalkan and T. Demirci, "The Effect of Neodymium-Doped Yttrium Aluminum Garnet Laser Irradiation on Rabbit Dental Pulp Tissue," Photomedicine and Laser Surgery, Vol. 28, No. 6, 2010, pp. 747-750. doi:10.1089/pho.2009.2702

[9] X. L. Liu, L. H. Wang, M. F. Wang, L. Liu, Q. Wang and J. H. Zhai, "Histomorphological Effects of Nd:YAG Laser for Debonding Ceramic Brackets on Rabbit Pulp," West China Journal of Stomatolology, Vol. 27, No. 4, 2009, pp. 413-416 (in Chinese).

\author{
Abbreviations \\ PHN: Postherpetic neuralgia \\ VAS: visual analog scale
}

